\title{
How to get ill, stay ill and die
}

\section{Andrew Hague}

President of CellSonic Limited.

Corresponding Author: Andrew Hague, President of CellSonic Limited

Received date: March 01, 2021; Accepted date: March 19, 2021; Published date: March 22,2021

Citation: A Hague. (2021) How to get ill, stay ill and die. Clinical Medical Reviews and Reports. 3(4); DOI: 10.31579/2690-8794/073

Copyright: (c) 2021, Andrew Hague, This is an open access article distributed under the Creative Commons Attribution License, which permits unrestricted use, distribution, and reproduction in any medium, provided the original work is properly cited.

\section{Abstract \\ This is your death plan. Choose the easy options. Go with the flow. Do what you want to do. This will get you off the endless conveyor. No more effort and it's all downhill. Be advised by advertisers, doctors who know nothing about food or exercise, a government that wants to squeeze you and business intent on profit. \\ If you are reading this thinking you can do the opposite, think again. You will be fighting powers you did not know exist. Perhaps you should be in a cave without money, friends or help. Survival in a civilised society is difficult. Only the brave can go against the grain. \\ There are three sectors: food, exercise and lifestyle. All three are waiting for you like monsters of the deep to suck you in and kill you. You think you are being looked after. Beware! \\ Keywords: food, exercise, lifestyle, sugar, dental, electrical fields, EMF, Schumann resonance, 5G, immune system, stress, emotions, brain damage}

\section{Introduction}

\section{Your life depends on:}

- Your mind - the thoughts in your head

- What goes into your body

- What you do with your body

The interaction between mind and body goes both ways. Thoughts affect the body and the condition of the body affects the mind. More than half the body is a microbiome. This consists of bacteria, viruses and parasites which live within us and we need them to keep our body working. Sensible decisions have to be made on what to put into the body to keep it healthy and that means suiting the microbiome, our residents. Fail to support them and the body fails.

This gives you the first clue on what to do to get ill; eat and drink the wrong stuff. It is easy to find because anything well-advertised and colourfully packaged can be assumed to be harmful if swallowed in quantity. The shops are full of cartons, cans and bottles on shelves at eye level. Generally, this is processed food. Look at the ingredients on the label. The more ingredients, the less good it will do you. To get ill, they are what you want. They are government approved, business approved and eaten by doctors. You will be aware that doctors are not taught about diet at medical school; only what drugs to prescribe.

\section{How to get ill:}

- Never drink water.

- All drinks must contain sugar or alcohol or both. Most cafés provide sugar on the table to add to drinks. There is no limit. Same with salt and pepper. Add salt. It will make you thirsty. Fizzy drinks will not quench your thirst but make you thirstier and more bloated.

- $\quad$ Prefer fried food

- Eat as much as you can.

- Smoking is deadly dangerous. Hallucinating drugs will cause damage so add them to the list. Don't worry about the expense; you will soon be dead.

- Never eat vegetables and fresh fruit. If you fancy orange juice, only have brands with added sugar.

Exercise would help to flush poisons out of the body that come from indigestible, sweet foods. You need those poisons to kill you. Exercise also pumps blood around the body, through the lungs to collect oxygen and to be cleaned in the liver and kidneys. Alcohol destroys the liver and is a common cause of death. Lungs loaded with tobacco tar will fail at the same time as causing heart failure. There is a race between the heart, lungs and liver to see which fails first. The rule with exercise is simple; don't do it because it would save your life.

Lifestyle is the path to the slippery slope. It is how you relate to others Most people want to belong. They show their membership by following others. Whether these actions help your mind and body is secondary to the security of knowing you have friends, people with whom to share a laugh. This group mentality is fundamental and present in all animals. The problem for humans comes from the industrialisation of food necessary to provide enough calories for an ever-expanding population.

In pre-agricultural times, sugar was almost unknown. It could be found in figs and fresh fruit and was a rare treat. The energy boost helped hunters and became part of the taste buds of humans. All energy taken in was used. None was stored as fat. When the agricultural revolution began followed by the industrial revolution, sugar cane production in the 
Caribbean and southern America escalated. West Africans were transported as slaves across the Atlantic. It was a triangular trade. Trinkets from British factories were the currency that bought slaves in Africa who were then loaded onto ships to be sold as malaria resistant workers in the sugar plantations. The third leg of the journey was to carry the sugar to sweet manufacturers in Europe. This was lucrative business driven by the quest for riches.

Sugar consumption today per person in America is six cups a week, far in excess of what is safe. With added sweeteners in almost everything, adding more sugar to food becomes poison. The body is unable to cope. The Islets Langerhans of the pancreas will stop producing insulin and diabetes will result. Excess energy is stored as fat, a lifesaving mechanism from a hundred thousand years ago to aid survival during famine by saving a lot of food to keep you going until the next lucky find. Nowadays, the fat accumulates to obesity and morbid obesity preventing a person moving. Death is inevitable. The sugar addict maintains consumption at a level that even the primeval hunter-gatherer would never have experienced. There is no automatic switch-off of the sugar crave when the body is idle.

The brain is $5 \%$ of the weight of the body, on average, and burns $25 \%$ of the energy used by the body. This means that using the brain without moving muscles increases the appetite but does not burn fat; it increases the appetite for more sugar. An example is car driving. Hardly any muscle power is used to drive a car, certainly not enough to get out of breath, and yet it makes you hungry. Roadside cafés serve sweet drinks and wrapped chocolate sweets to eat as you go on your journey. For this, our bodies were not intended and yet for some people there is pleasure in driving, they think they are doing something worthwhile. It may also be letting the brain think the body has gained super strength. Look at the delusion of racing cars. Driving is one of the most self-damaging activities of modern times. Quite apart from the risk of injury in a crash, there is serious health damage from sitting tense without the commensurate muscle movements. Add this to your list of things to do to get ill and stay ill.

\section{Electrical fields}

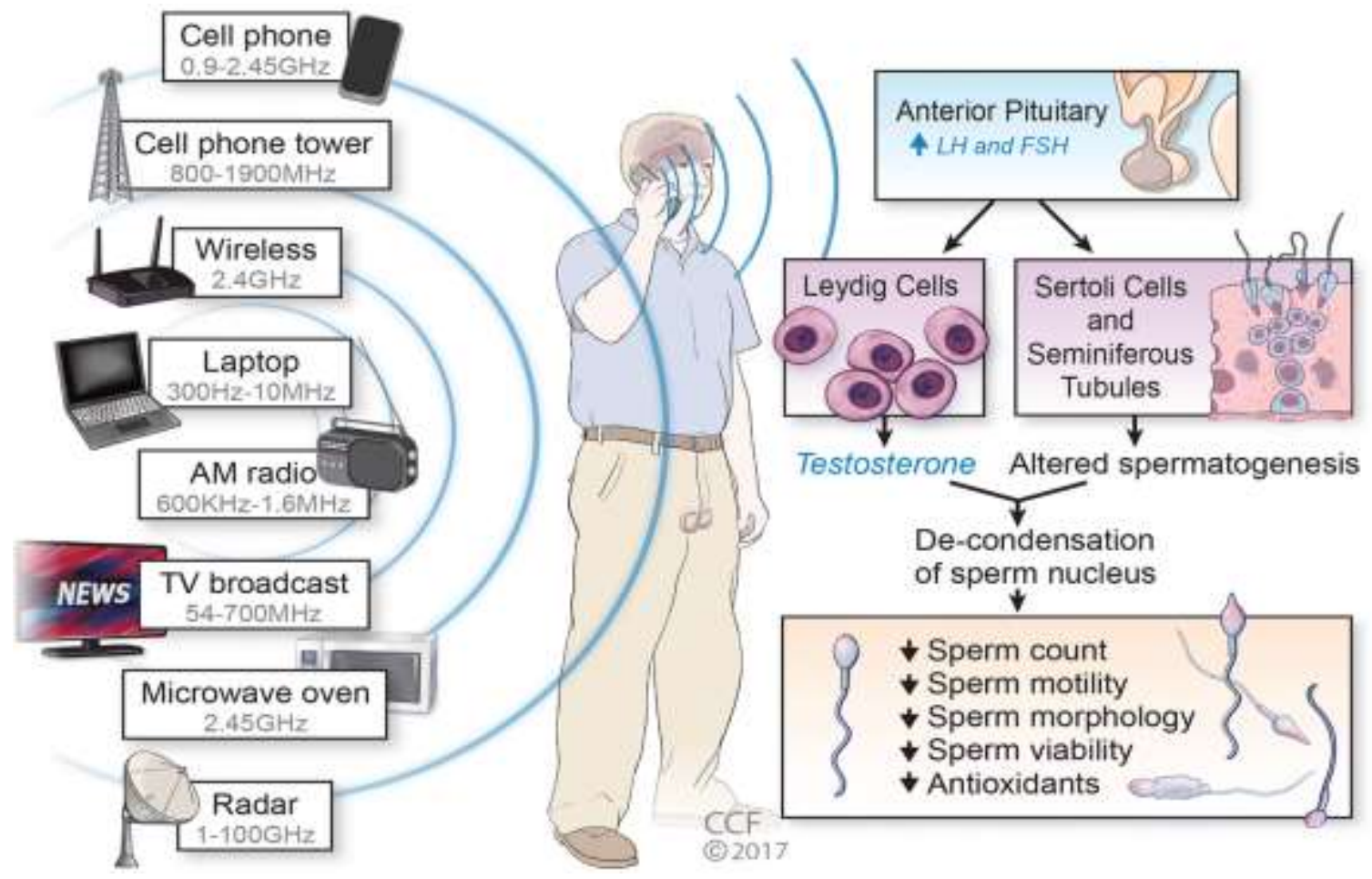

Illustration attributed to Joel M. Moskowitz, Ph.D.

In an industrial society there is a modern cause of disease everywhere. It is encouraged by all governments and enthusiastically welcomed by most people. This is the wireless telephone system. The damage of electrical fields has long been known and ignored but the surge of smartphones and wireless modems has created the biggest health threat, bigger than the covid pandemic. This is far more dangerous than bad food, pollutants in water and air and poisons in cosmetics and cleaning materials. The electrical fields, known as electromagnetic fields and abbreviated to EMFs affect the brain. The effect is accumulative. A bit today. Another bit tomorrow and so on until you get headaches and feel ill without any obvious cause. A visit to the doctor produces a drug which has no benefit, because it does not reverse the damage, and that drug will present the immune system with a further problem until the load on the immune system forces it to shut down.

Doctors have an interesting ploy when they do not know the cause of an illness. They guess what the cause may be, check the recommended drug on their government's website and prescribe it. One of three things can happen: nothing, an adverse reaction or a cure. If the drug cures, by reverse logic, they have diagnosed the illness. If the reaction was adverse, they take the patient off that drug and try something else. If nothing happens, they say the patient failed to respond and will either increase the dose or try something else. In all cases, the doctor has to prescribe a drug. They are puppets of a pharmaceutical regime.

There are no prominent academic studies on the dangers of EMFs for the simple reason that all academic study has to be paid for and no government or company will pay for research that is not profit related or could contradict government policy. University research relies on governments and corporations. Successful professors are those who can prise sponsorship grants for projects that support politicians and profits. Nevertheless, the work of Lloyd Burrell of ElectricSense ${ }^{[1\}}$ and Nathan Crane ${ }^{[2]}$ of Global Cancer Symposium reveals the danger of ignorance and corruption. 


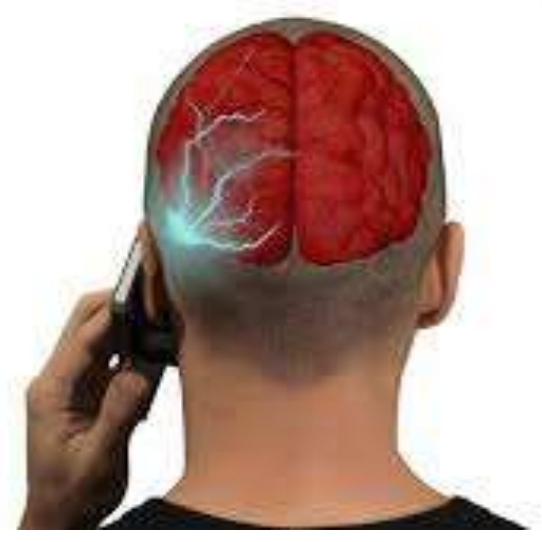

Picture attributed to Vest

The manner in which medical research is done is also biased by pharmaceutical methods. All drugs have side effects and the research is primarily to find the side effects and secondarily aimed at finding if the drug works. If the question is whether holding a phone to one's ear damages the brain and 100,000 people are questioned, not everyone holds a phone to the ear many hours a day so the finding could be that only $0.01 \%$ of people are affected which would mean that the phone is safe.

If one person has a phone clamped to the ear for four hours a day and after a month is found with brain damage at the same side as that ear then the phone is certainly the cause of the damage. This test was done at Bradford University by Professor Raed al Abd Hameed [3] on a phantom head with brain material inside it. I never discovered whether the brain material is synthetic or pulverised cadaver but the resultant advice was that the

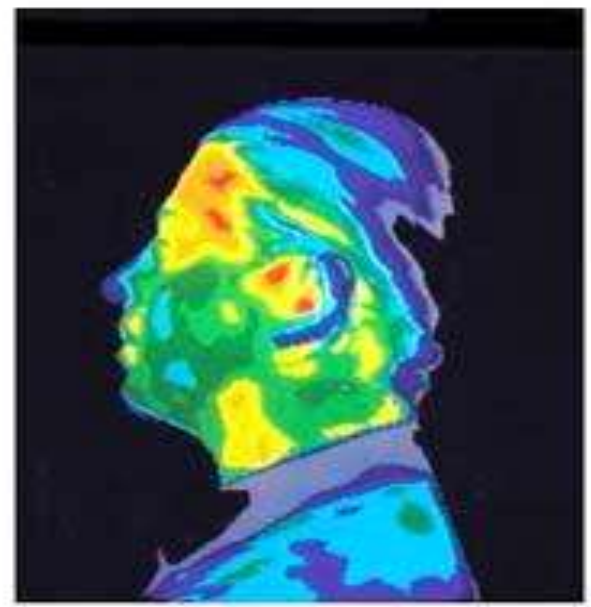

Thermographic Image of the head with no exposure to harmful cell phone radiation.

\section{Illustration attributed to Dr Diane Brain Health}

The EMFs are causing physical damage to the brain. Six minutes is the longest time to keep a phone to your head before brain damage occurs and the damage burns a small bit of brain every time, bit by bit. Electrical longest time to safely have a phone to the ear is six minutes. Best to use loud speaking or air ear phones to avoid damage. Finding a peaceful way to die is tricky. Brain damage starts with headaches and just gets worse.

To aid your death plan, you do not have to change your behaviour. You will already have immersed yourself in the digital world. You have at least one smartphone and a laptop. At home there is a wireless modem and you sleep with your phone switched on under your pillow although you don't know why. You are captivated by the endless supply of information. Maybe one day something exciting will happen but it never does but in case it does you do not want to miss it. This is addiction of the conscious mind. All useful thought has been pushed aside by the torrent of stories to the extent that you have lost the ability to think for yourself. You have lost your mind. Staying healthy requires conscious decisions all day and every day. Now you cannot manage yourself.

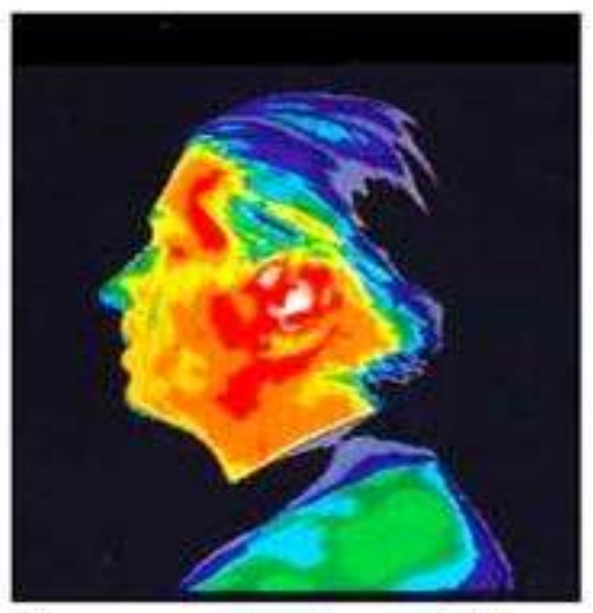

\section{Thermographic Image of the head after a 15-minute phone call. Yellow and red areas indicate thermal (heating) effects that can cause negative health effects.}

waves from a modem hit your brain continuously. Some people sense it more than others. Everyone is affected and over time everyone is injured. It is cumulative, burning piece by piece until no brain cells are left. The latest $5 \mathrm{G}$ telephone transmitters are the worst of all. If they are not in your neighbourhood yet, they are coming. 


\section{How mobile phone radiation penetrates the brain}

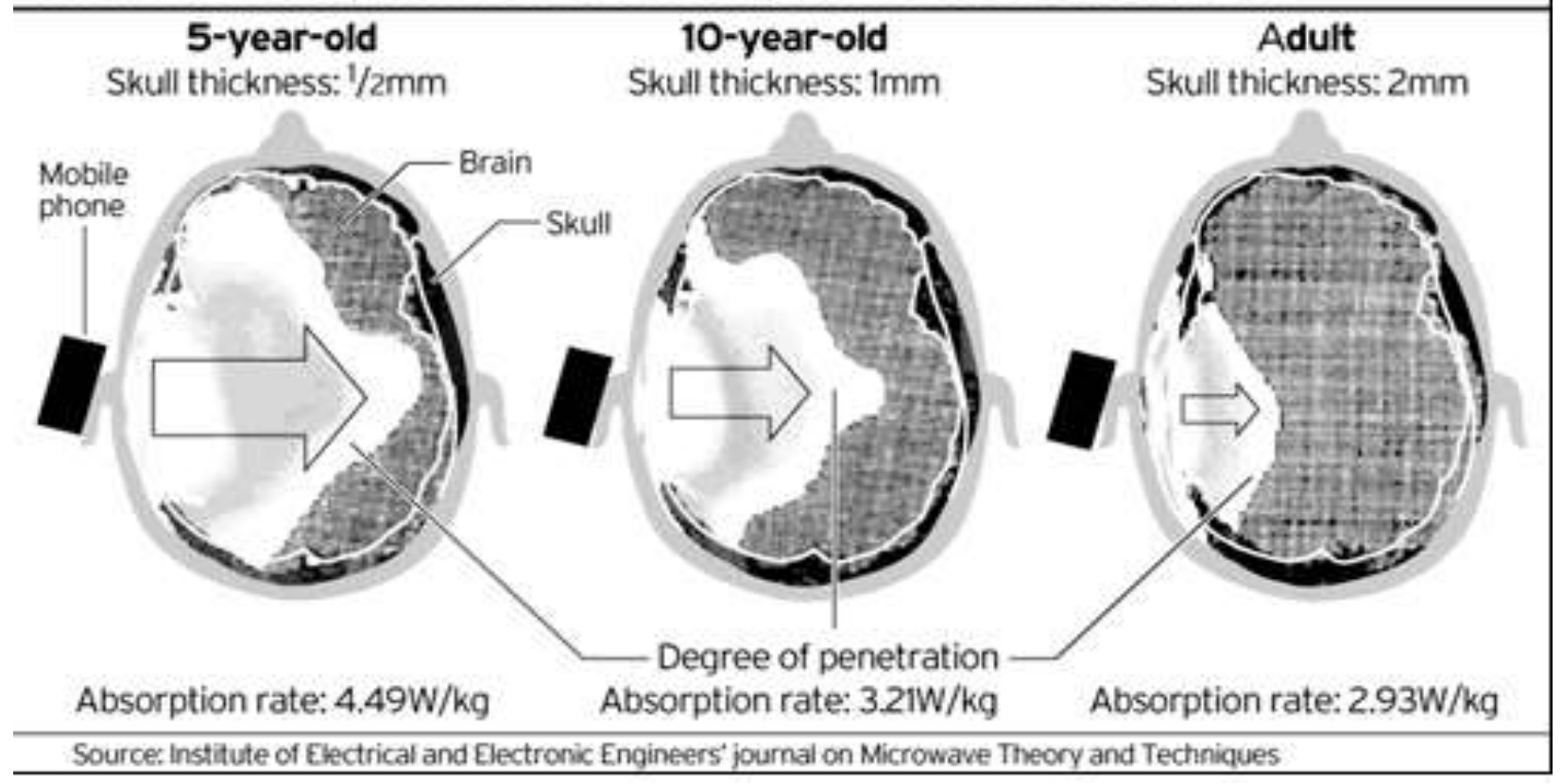

\section{Illustration from Penn State}

When your electricity supplier offers a smart meter, accept because it is a killer. It will radiate a strong signal to the mast somewhere near your house and that signal will incrementally damage your health. Likewise, the enthusiasm for the Internet of Things enabling your fridge to automatically reorder will increase the EMFs in your living space. The opportunity to destroy your immune system and get ill is abundant and encouraged by governments and suppliers you trust.

All life on earth is subject to the electrical field of the Schumann resonance radiating from the ionosphere at $7.83 \mathrm{~Hz}$, a very long wave length of low frequency. It passes through our bodies. If it does not, we feel ill. The sun's radiation is similarly long and natural. Life evolved with it. It is the man-made electrical radiation of shorter wave lengths that are dangerous. They do not pass through the body; they stay in the body. Telephone WIFI transmitters have progressed from short to shorter wave lengths from the early $2 \mathrm{G}$ to $3 \mathrm{G}$, then $4 \mathrm{G}$ and now $5 \mathrm{G}$ with a $10 \mathrm{~mm}$ wave length is being installed in cities. The danger of $5 \mathrm{G}$ is so harmful that the only advice is to avoid it if you want to stay healthy. ${ }^{[12]}$ Move from the city, the town or wherever there is better connectivity and accept that mobile phones are not part of your life anymore. But you want a death plan and thanks to scientific progress, the power to kill you and everyone else is being installed as fast as investment allows. The only argument you hear about $5 \mathrm{G}$ was that if it is made by Huawei it may be spying on behalf of the Chinese Communist Party.

Without making any changes to your daily life, you are already getting ill, will stay ill and will certainly die prematurely. You are following a path you chose because you want to be a member of your community and do what others are doing. They too will die prematurely.

\section{Survival}

Throughout history, human society has survived by the majority of people finding a way to collaborate and stay safe. Changes were not always improvements. It is argued that the quality of life in pre-agricultural times was better than the drudgery of farming and the hunter-gatherers had more nutritious food from a wider variety of plants. Nevertheless, the change survived because it fed a larger population and it is the survival of the species that determines evolutionary success.

What we see now is a community supported, scientific shift that imperils the species. The time lag between damaging the immune system, getting ill and dying is long enough for the link between cause and effect to not be understood by the masses. Even a lag of two weeks between covid-19 infection and symptoms has been sufficient for the virus to infect the world. In America, the main cause of death is heart disease and second is cancer. Both are avoidable lifestyle diseases. In other words, the victim had a choice. From being stressed and impairing the immune system to allowing mutant cells to proliferate to form a tumour big enough to hurt can be ten years.

Stress is the main cause of cancer and it can be physical or emotional. From what I see of patients coming to CellSonic, most suffered emotional stress. A lady in Poland asked me about this because her husband had cancer and I told her that it was usually divorce but as they were still married it must have been something else that damaged her husband. "No," she said, "It was divorce. Our daughter's divorce and my husband was more upset than she was. That was ten years ago."

The technical disturbance from EMFs is severe. Equally as damaging is the isolation of individuals struggling with an overload of stories on the news and social media. Atrocities on the other side of the world now penetrate our consciousness in real time. On top of that, entertainment in films has violence in excess of normal life. This is the direct opposite of the comfort humans evolved to need in the security of an extended family under the guidance of grandparents. Modern life for many is abnormal.

Why disturbing escapism steers people in their non-working life, requires study. Given a choice between a quiet walk in the countryside and a rowdy football match followed by getting drunk, the majority prefer the football match. This tension seems to be equal between male and female. Is working life insufficiently stimulating? Are we inherently aggressive? [4].

\section{Turn around and look up}

Suicide is fortunately rare. There is a ten-minute period during which the person will kill themselves and if they can be supported through that time 
they will survive and be grateful for the rescue. Choosing to die by getting ill does not happen. I am sure that you did not read this article to find a way to die but you do acknowledge that most people are launching themselves down the slippery slope to death.

If you have stood on the brink, looking into the abyss and want to haul yourself back to health, it can be done. It is up hill and you will part company with the throng until they too see the sense in what you are doing.

Here's the Health Plan:

$$
\begin{array}{ll}
> & \text { Happy thoughts } \\
> & \text { Protect the brain } \\
> & \text { Feed your body } \\
> & \text { Exercise } \\
> & \text { Repair }
\end{array}
$$

\section{Emotions}

Happy thoughts mean positive thinking. Studies of spontaneous cures of cancer find that $70 \%$ of the cases involved the person getting their emotions into a positive state of mind. It is this mental force that has more effect on health than anything else.

In the modern world, it is about avoiding mental stress. There is nowhere to hide. This is not like childhood when you ran to Mummy and wrapped your head in her apron. Work is stress. If it is not, you are not trying hard enough. Laws govern everything you do. Official letters tell you in bold letters that failure to reply will lead to prosecution. You are expected to achieve a standard as defined by photos and statements in Instagram. The least you can expect is humiliation. No one will praise you. It is you versus everyone you know. The answer is not to jump off the bridge. You have to switch off all connections. No news. No TV. No Facebook and so on. Detach because you are being eaten alive.

Devoid of messages, begin at the beginning. Go for a walk. You are not answerable to anyone. Say "Hello!" and smile. They will be surprised to meet a friendly stranger because they like you are also bombarded by troubles. You have just helped someone. Walk on and remind yourself that if its worrying, it won't stick. You are starting where you left off when you were five. That was when school started and since then it has been learning, exams, tests and taxes. Now it is for you to choose. You are walking and where you go is where you want to go, not where you are told to go.

\section{Brain damage}

Let your brain be damaged and repair is difficult. It is an electrical bionic machine protected from physical impact by a skull but no defence against short wave, high frequency electric waves because when the brain evolved there were no high frequency electric pulses. There were only low frequency pulses from the ionosphere which the brain needed to function as an electrical switching machine. Bombarded with the wrong current, it burns out.

A lot of good advice is available from Lloyd Burrell [1], Nathan Crane [2] and many others. Ideally you will move to a place where there are no electrical gadgets and if you find that place, keep it secret. Millions more are soon going to realise they too need to be there as well. After the damage from negative thoughts, EMFs are the most dangerous things in the world today. They are not bacteria or viruses. There is no antibiotic or vaccine to stop them or cure their damage. This is the consequence of engineering without testing the long-term effect on health. [5]. Quote from FCC, in USA, 'We don't deal with humans, only frequencies' [5].

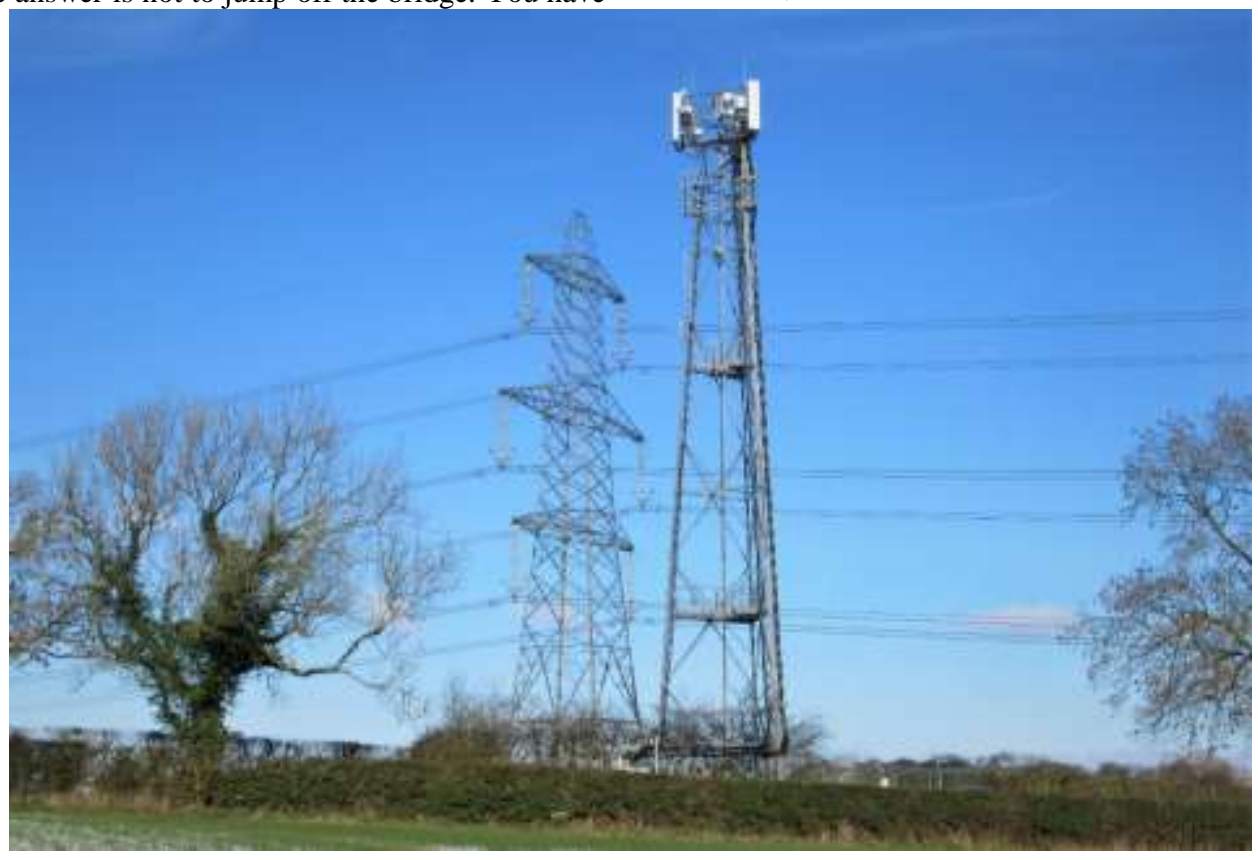

High voltage powerlines with a mast for microwave signals. A formidable combination.

Easingwold, North Yorkshire, England. Photo by author.

Erect a metallic shield around your house to keep out the electrical radiation and you will also block the long frequencies from the Schumann Resonance which are essential. Humans and all life are electrically sensitive. Fifty years ago, this was an irrelevant subject. Today wireless interconnectivity is everywhere and expanding. Our machines need it and we don't. This is a killer bigger than any weapon. It is being installed globally and deaths will follow in ten to fifteen years; the time it takes for cancer tumours to be big enough to kill.

\section{Food and drink}

Studies of old people always want to know what they eat assuming that their diet is the secret to longevity. It is simpler than that; people eat local produce and live to a hundred or more. What the old have in common is 
living in harmony with the land on which the food grew. Urban living makes this impossible but the relationship can still apply with local markets and organic food.

There is an abundance of advice on diets [6]. Dr Merle Loudon publishes a weekly newsletter. To subscribe email DrMEL11@aol.com .

You must avoid sugar and alcohol. Modern food has enough calories without added sugar. There is no safe limit for alcohol [7].

\section{Exercise}

This is new. Fifty years ago and earlier, people went about their daily life never thinking about exercise. They didn't need to. Life was physically arduous. As an old man in the south of Italy told an interviewer looking for the secret of longevity, "Back then in my youth, our bodies were active and out brains were still; now our brains are active and our bodies are still." Body movement has been eliminated with devastating consequences.

The exercise continuum and the role of doctors is explained in my article [8] showing that cyclists in their 70s have an immune system equivalent to people in their 20s. It is the exercise that keeps them young.

The healthy exercise has to be relaxed. Training for the Olympics and getting stressed in a gym can be injurious to the immune system. Exercise is best done outdoors. Let vitamin D from the sun reach the skin. It is the best supporter of the immune system and pills are no substitute. Fresh air into the lungs results in clearer blood. Under pressure in a gym to do a prescribed number of jerks and steps is as bad as going to work in a coal mine. You breath in the air exhaled by others.

\section{Repair}

All animals, including humans, have an immune system, the automatic diagnose and repair system to maintain health. Communication between the brain and body is along nerves and the language is pain. You know when you are not right. There are two types of injury: acute and chronic. injury, you were not infected and otherwise healthy. The nerves scream for help and there is a rush to stop bleeding and prevent infection invading the wound.

Chronic conditions are those that drag on for years and never get better. For this, you go to the doctor who will prescribe a medicine. You will be permanently on that medicine and believe your life depends on it. Everyone on aspirin daily does not have an aspirin deficiency so aspirin is not what is missing. Why, then, is it taken? Ask the doctors who have no idea what they are doing. A chronic condition is the result of failure to understand the causes which are almost certainly the result of an incorrect lifestyle. Ideally, the immune system will correct the illness but the condition may have deteriorated beyond the threshold at which the immune system is able to operate [9].

Modern medicine is based on biochemistry and surgery. The pharmaceutical industry, generally called Big Pharma, dominates medicine by advising regulators and sponsoring education. They have nothing to support the immune system. To Big Pharma, a chronic disease is an enduring market. Their objective is sales. A cure stops sales.

Chronic conditions almost always involve a mental state and a body failure. Both the mind and the faulty organs have to be corrected; solving only one but not the other is not enough. The body including the brain is an electrical being generating about 100 watts of energy at rest. This is biophysics. Chemistry does not solve an electrical problem. A biophysical solution is needed.

This technology has long been understood and over the last hundred years has developed into the state-of-the-art CellSonic VIPP machine. The technology of CellSonic originated in lithotripters used in all hospitals worldwide with millions of people treated for the last forty years for kidney stones without side effects. Its safety is beyond doubt. The technology is accepted by urologists, orthopaedics and physiotherapists. CellSonic is used on wounds that fail to heal, broken bones that do not bond and nerve repair such as severed spinal cord. The latest discovery is the ability to stop cancer.

Acute is sudden emergency such as a crash or cut. Up to the point of

\begin{tabular}{|c|c|c|c|}
\hline Popular treatments & $\begin{array}{c}\% \\
\text { success }\end{array}$ & protocol & comments \\
\hline $\begin{array}{l}\text { Wounds, internal and } \\
\text { external including } \\
\text { diabetic ulcers }\end{array}$ & 95 & $\begin{array}{l}100 \text { pulses per square } \\
\text { centimetre at energy level } 4\end{array}$ & $\begin{array}{l}\text { Kills infection on and under the wound. Increases } \\
\text { vascularisation. }\end{array}$ \\
\hline Covid-19 & 85 & $\begin{array}{l}\text { Same as wounds, killing } \\
\text { viruses }\end{array}$ & The sooner the better. No drugs. Safe on the lungs. \\
\hline Pseudarthrosis & 90 & $\begin{array}{l}\text { Patient anaesthetised. Energy } \\
\text { level } 10.1500 \text { pulses both } \\
\text { sides of the fracture. }\end{array}$ & $\begin{array}{l}\text { Often used with metal supports in place. Avoids additional } \\
\text { surgery and risk of infection. }\end{array}$ \\
\hline Back pain & 85 & $\begin{array}{l}\text { Aim at and around area of } \\
\text { pain. Energy level } 5.600 \\
\text { pulses. }\end{array}$ & Maybe the most common pain. \\
\hline $\begin{array}{l}\text { Tennis elbow, calcified } \\
\text { shoulder }\end{array}$ & 90 & 1000 pulses at energy level 6 & One treatment \\
\hline Heel spur & 90 & 1000 pulses at energy level 8 & Usually local anaesthetic, one treatment \\
\hline $\begin{array}{l}\text { Erectile dysfunction and } \\
\text { Peyronie's }\end{array}$ & 75 & $\begin{array}{l}\text { As for a wound with six } \\
\text { treatments fortnightly }\end{array}$ & Avoids drugs and surgery \\
\hline $\begin{array}{l}\text { Toe nail fungus and } \\
\text { verruca }\end{array}$ & 95 & Same as wounds & Kills the infection \\
\hline Cancer & 80 & $\begin{array}{l}300 \text { pulses per tumour at } \\
\text { energy level } 4\end{array}$ & $\begin{array}{l}\text { Usually metastasised. Treat all areas and around. Important to } \\
\text { get good nursing to repair damage caused by the cancer and } \\
\text { wrong treatments. Success rate is higher the sooner the } \\
\text { cancer is treated. }\end{array}$ \\
\hline
\end{tabular}

All CellSonic doctors understand the support of the mind in healing. A positive attitude is essential along with diet and exercise. Just pressing the button on the machine is not the entire solution. The machine corrects the condition that the immune system is unable to deal with. This puts the 
condition within the range of the immune system and the healing continues. CellSonic works with the body and mind.

\section{Dental}

An interesting observation of patients with chronic disease, cancer included, is that they often have infection between the teeth and gums and the teeth and bone. Dental hygiene has little effect and there is no straight forward explanation of how some people get the infections and others
Don't. It is called periodontal disease. The only simple cure is CellSonic aimed through the cheeks into the gums at the root of the teeth. The pulses penetrate and at the recommended protocol of 100 pulses per tooth, the teeth are not damaged. To remove the dental infection is important because the teeth are linked to all the organs of the body. Treating a cancer patient who has dental infection is futile unless the dental infection is also removed. Here is a chart showing the links between the teeth and the body.

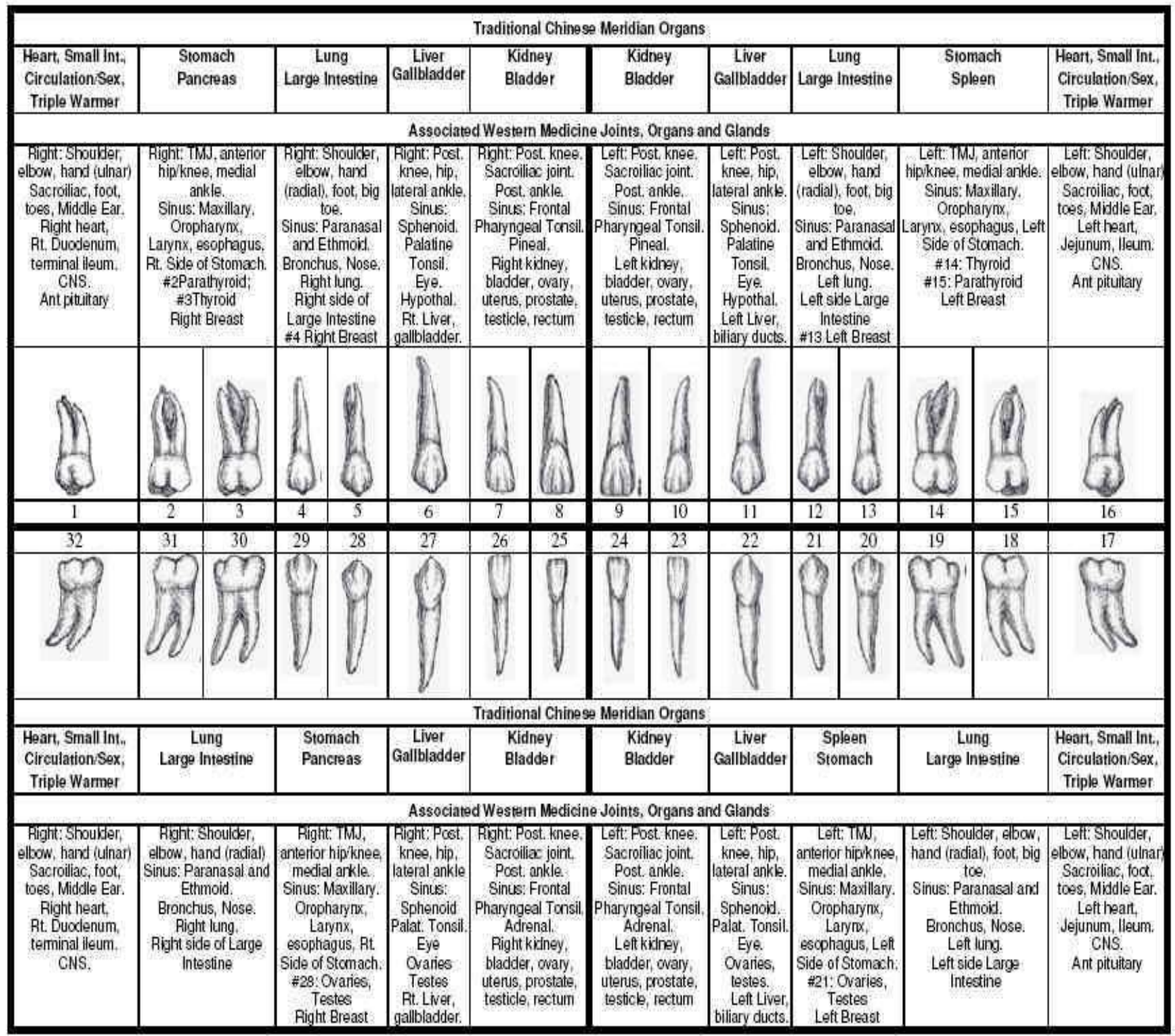

Acumeridian Tooth-Organ Relationships from various sources including Gleditsch and Klinghardt (www.NeuralTherapy.com). Compiled by Dr. Ralph Wilson

Half the population has periodontal disease. Antibiotics do not cure it, only CellSonic is effective [10].

See the paper by Dr Joseph Choukroun in France ${ }^{[11]}$ about reversing the necrosis of the mandible of a patient whose jaw bone had died after ten years of cancer drugs. He was able to fit teeth implants allowing the patient to eat normally. Without CellSonic the options were amputation of the jaw or death.

\section{Conclusion}

Premature death is avoidable. If you cannot sort out your lifestyle, go to a CellSonic doctor. They will advise on diet, exercise and emotional stability. Where biophysics are needed, they have the necessary equipment. Having got back on track, stay there. Make the effort, it is an effort and there is hope for the determined. 
The references below link to further information. This is more than your local doctor will tell you.

\section{References}

1 https://www.electricsense.com/ this website contains a wealth of information about EMFs and must be studied and supported.

2 Nathan Crane https://nathancrane.com/ links to videos with many doctors

3 Bradford University https://www.cellsonicmedical.com/download/Cancer/3\%20Cancer\%20and\%20wounds $\% 20$ are\%20similar.pdf

4 Inherent brain problems https://www.cellsonicmedical.com/download/Inherent_Brain_Problems.pdf

5 'We don't deal with humans, only frequencies' Lawsuits Expose FCC's Failure to Weigh Evidence of Health Impact of Wireless Technology $\bullet$ Children's Health Defense

6 Critical Non-Invasive Treatment to Heal Grade III and IV Cancer First edition, published 2021 By Dr. Merle Loudon Cover design by Reprospace.com Copyright (C) 2021, Dr. Merle Loudon Paperback Edition ISBN-13: 978-1-952685-08-8

7 Alcohol https://lupinepublishers.com/medical-sciencejournal/fulltext/the-ins-and-outs-of-elimination.ID.000111.php

8 The exercise continuum and the role of doctors https://juniperpublishers.com/oajggm/pdf/OAJGGM.MS.ID.555 622.pdf

9 Threshold of body and mind https://www.cellsonicmedical.com/download/Thresholds $\% 20$ of $\% 20$ body $\% 20$ and $\% 20$ mind.pdf

10 Periodontal disease https://www.cellsonicmedical.com/dental.html.

11. Necrosis of the mandible https://www.cellsonicmedical.com/download/Osteonecrosis_treatment.pdf $5 \mathrm{G}$ video is essential viewing https://articles.mercola.com/sites/articles/archive/2019/05/11/5gapocalypse.aspx?utm_source=dnl\&utm_medium=email\&utm_co ntent=art1\&utm_campaign=20190511Z1_UCM\&et_cid=DM286 115\&et_rid=613049201

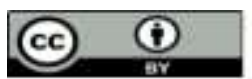

This work is licensed under Creative Commons Attribution 4.0 License

\section{To Submit Your Article Click Here: Submit Manuscript}

DOI: $10.31579 / 2690-8794 / 073$
Ready to submit your research? Choose Auctores and benefit from:

* fast, convenient online submission

* rigorous peer review by experienced research in your field

* rapid publication on acceptance

* authors retain copyrights

* unique DOI for all articles

* immediate, unrestricted online access

At Auctores, research is always in progress.

Learn more www.auctoresonline.org/journals/clinical-medical-reviewsand-reports 